\title{
Betamethasone and the Rhesus Fetus: Effect on Lung Morphometry and Connective Tissue
}

\author{
JEANNE C. BECK, ${ }^{(35)}$ WAYNE MITZNER, JOHN W. C. JOHNSON, GROVER M. HUTCHINS. \\ JEAN-MICHEL FOIDART, WILLIAM T. LONDON, AMOS E. PALMER, AND RACHEL SCOTT \\ Division of Maternal and Fetal Medicine, Department of Obstetrics and Gynecologv, the Department of Pathology of \\ the Johns Hopkins University School of Medicine; the Department of Environmental Health Sciences of the Johns \\ Hopkins University School of Hygiene and Public Health. Baltimore. Maryland; and the Infectious Disease Branch of \\ the National Institute of Neurological and Communicative Disorders and Stroke, and the Laboratory of \\ Developmental Biology and Abnormalities of the National Institute of Dental Research, Bethesda, Maryland, USA
}

\begin{abstract}
Summary
Pregnant rhesus monkeys (Macaca mulatta) at 67 to $85 \%$ of term pregnancy were treated with betamethasone for 3 days and then delivered by cesarean section. These treated fetuses had larger lung volumes $(32.6 \pm 1.8 \mathrm{ml} / \mathrm{kg}$ of body weight) compared to gestational age-matched controls $(22.9 \pm 3.2 \mathrm{ml} / \mathrm{kg}$ of body weight; $P<0.025$ ) but no alterations in surfactant properties as measured by amniotic fluid $\mathrm{L} / \mathrm{S}$ ratios, alveolar deflation stability, or lung phosphatidylcholine. These findings suggest that betamethasone effects an increase in fetal lung volume by some method other than alteration in alveolar surfactant concentrations. Results also demonstrated an $11 \%$ increase in the collagen to elastin concentration in the treated fetuses as compared to the control animals $(P<0.01)$, suggesting alterations in lung connective tissue. Morphometric studies done on the air-fixed inflated lung demonstrated a decrease in the number of alveoli per unit volume of lung among the treated animals $\left(0.95 \pm 0.07 \times 10^{6}\right)$ compared to the control animals $\left(1.19 \pm 0.08 \times 10^{6} ; P<0.025\right)$ and a reduction in the mean surface area of the lungs of the treated animals $\left(506 \pm 10 \mathrm{~cm}^{2}\right.$ per $\left.\mathrm{cm}^{3}\right)$ compared to the control animals $\left(561 \pm 9 \mathrm{~cm}^{2}\right.$ per $\left.\mathrm{cm}^{3} ; P<0.005\right)$. These findings suggest that at least part of the increased maximal lung volumes is related to increased alveolar distensibility. Together, these pressure volume findings, biochemical studies, and morphometric analyses indicate that a major effect of betamethasone on the rhesus fetal lung is to alter lung connective tissue characteristics. Alterations in lung surfactant appear to be of less functional significance in this rhesus fetal model. The disparity between these findings and other animal studies might be due to differences in species, the preparation, or the method of glucocorticoid administration.
\end{abstract}

\section{Speculation}

Maternal betamethasone treatment produces alterations in the connective tissue properties of the developing fetal lung, which could have long-lasting effects on lung mechanical properties.

Acceleration of fetal lung development by antenatal administration of glucocorticoids has been demonstrated in a number of clinical and animal studies (2). Most previous studies suggest that glucocorticoids act by accelerating the synthesis and release of fetal lung surfactant (2). However, we have observed that the major effect of betamethasone on fetal rhesus lung is to increase the total lung capacity, with less significant surfactant alterations $(14,15)$. In a more recent study, we compared air and saline fluidfilling characteristics in control and betamethasone-treated rhesus fetuses (21). Increased lung volumes were observed in the steroidtreated fetuses, both during air and saline filling. This latter observation supports our hypothesis that the functional effects of betamethasone are primarily upon lung structural characteristics. rather than upon alveolar surfactant.

In this animal model, betamethasone appears to accelerate lung maturity by inducing structural changes that increase total lung volume. The question arises, however, as to the mechanism for this increase in lung capacity. Lung capacity can be increased either by making the inflatable units more distensible or by increasing the number of inflatable units (recruitment). To attempt to answer this question, we have performed morphometric analyses on lung tissue from betamethasone-treated fetuses. In addition, collagen and elastin have been extracted and quantified from aliquots of fetal lung, to determine whether or not alterations in fetal lung connective tissue elements might be associated with betamethasone treatment.

\section{MATERIALS AND METHODS}

Fourteen pregnant rhesus monkeys (seven pairs of Macaca mulatta), matched for duration of gestation, were used for these studies. Details regarding the determination of the duration of pregnancy and the care of the pregnant females have been reported previously (15). The pregnant animals were separated into two groups: group I mothers received isotonic saline (Med Tech, Inc., Elwood, TX) intramuscularly $(0.3 \mathrm{ml})$ daily for 3 days before preterm delivery. Group II mothers received $1 \mathrm{mg}$ of betamethasone phosphate and $1 \mathrm{mg}$ of betamethasone acetate (Celestone Soluspan; Schering Corp., Kenilworth, NJ) intramuscularly $(0.3$ $\mathrm{ml})$ for the same duration of time. This daily dosage, which is one-sixth that used in clinical obstetrics, was chosen on the basis that the rhesus fetal weight is about one-sixth that of the human fetus. Delivery was accomplished by cesarean section ir all cases. according to previously described techniques (15). Gestational age at delivery varied between 67 and $85 \%$ of term pregnancy (comparable to 28 to $34 \mathrm{wk}$ of human pregnancy), with one animal from each group being delivered at 110, 115, 120, 125, 130, 135, and 140 days' gestation, respectively. Amniotic fluid samples were obtained before delivery. The fetal trachea was clamped upon delivery to prevent spontaneous fetal lung inflation. Death occurred shortly thereafter. All data were collected without prior knowledge as to the gestational age or treatment of the animal. Fetal body weight, crown-heel length, crown-rump length, head circumference, trimmed placental weight, and sex were determined.

Upon completion of the pressure volume studies on fetal lungs. the following organs were removed, blotted dry, placed in preweighed, covered vessels and weighed to $0.01 \mathrm{mg}$ on an analytical balance: lungs, adrenals, kidneys, thymus, liver, and spleen.

The amniotic fluid samples were processed and the lecithin/ sphengomyelin $(\mathrm{L} / \mathrm{S})$ ratio determined, as described previously (15). 


\section{PRESSURE-VOLUME STUDIES}

After fetal death by asphyxiation, the trachea was unclamped and cannulated. Pressure volume studies were then performed with the thorax intact and by previously described methods (15). Maximal lung capacity was achieved by inflating the lungs to 50 $\mathrm{cm}$ of water transpulmonary pressure (TPP) and maintaining that pressure for $4 \mathrm{~min}$ (15). An inflation pressure of $50 \mathrm{~cm}$ of water would not be expected to cause lung damage in these fetal lungs. Indeed, we have shown that nearly identical deflation pressure volume curves can be obtained with an inflation pressure of 30 $\mathrm{cm} \mathrm{H}_{2} \mathrm{O}$. even when separated in time by an intermediate inflation to $50 \mathrm{~cm} \mathrm{H} \mathrm{H}_{2} \mathrm{O}$ (W. Mitzner and J. W. C. Johnson, unpublished observations). The values for pressure volume analyses were taken from the second inflation and deflation limbs. After these studies of the mechanical properties of the lung and thorax, the thorax was opened and the left and right lungs were removed and weighed. They were then separated. The right lung was utilized for biochemical studies. The left lung was used for morphometric studies.

\section{MORPHOLOGIC' STUDIES}

After the pressure volume studies, the lungs were removed. and the right lung was used for biochemical studies, as noted above. The left lung main stem bronchus was cannulated, and the left lung was fully inflated and then deflated between 0 and $30 \mathrm{~cm}$ of water TPP. The lung was held at $30 \mathrm{~cm} \mathrm{H}_{2} \mathrm{O}$ pressure in a $37^{\circ} \mathrm{C}$ oven for 24 to $48 \mathrm{hr}$ to achieve fixation. After fixation, thick coronal sections were cut from the upper and lower lobes. These sections were embedded in paraffin: $6 \mu \mathrm{m}$ sections were cut and stained with hematoxylin and eosin. Measurements of alveolar numerical density and alveolar surface area density were then done by using a square grid, randomly placed at seven to ten different locations, and by averaging the countings. The alveolar surface area/unit volume of lung was determined as described by Weibel (29) and is directly proportional to the number of intersections of the test lines with alveolar walls and inversely proportional to the total length of the test lines. The test lines in this case are the perpendicular lines of the grid. Alveolar number per unit volume of lung was determined by counting the number of alveoli within the large square. Using the formula of Weibel and Gomez. (30), with a shape factor of 1.55 , we calculated the number of alveoli per unit volume of lung tissue.

\section{BIOCHEMICAL STUDIES. PHOSPHOLIPID ANALYSES}

The right lung was weighed, homogenized, and lyophilized, as described previously (15). Phospholipids were extracted by the method of Folch et al. (10), as modified by Cheek (6). Aliquots of the purified lipid extract were chromatographed in one dimension on silica gel $\mathrm{H}$ thin-layer plates $(0.5 \mathrm{~mm}$ : Applied Science Laboratories. Inc.. State College, PA), using the solvent system of Goldner and Brumley (12). After visualization with iodine vapor and scraping. phosphatidylcholine and sphingomyelin were quantified by the phosphorus assay of Parker and Peterson (24). An aliquot of the total lipid extract was also analyzed for total phospholipid phosphorus by the same procedure (24). Phospholipid concentrations were obtained by multiplying the phosphorus concentration by 25 (i.e., assuming an average molecular weight of 800 ).

\section{DNA ANALYSES}

DNA analyses were performed by the fluorometric method of Kissane and Robbins (16), as modified by Cheek (7), using calf thymus DNA (Worthington Biochemical Corp.. Freehold, NJ) as the standard.

\section{COLLAGEN AND ELASTIN MEASUREMENTS}

Collagen and elastin were separated by treatment of the tissue with hot alkali (19) or by autoclaving each specimen in $4 \mathrm{ml}$ of distilled water (9). Both procedures gave identical results. After hydrolysis in $0.1 \mathrm{~N} \mathrm{NaOH}$ for $45 \mathrm{~min}$ at $95^{\circ} \mathrm{C}$ of a preweighed amount of lyophilized lung homogenate. the supernatant fraction containing collagen and the insoluble (residue) fraction containing elastin were separated by centrifugation at $20,000 \mathrm{rpm}(45,000 \times$ g) for $30 \mathrm{~min}$. The pellet was washed with distilled water. The two supernatants were combined, dialyzed, and lyophilized. Both fractions were then hydrolyzed in $6 \mathrm{~N} \mathrm{HCl}$ for $24 \mathrm{hr}$ at $110^{\circ} \mathrm{C}$. Aliquots of these fractions from each lung were analyzed on a Durrum D500 amino acid analyzer. The amino acid composition of the residue fraction always corresponded to the known amino acid composition of pure elastin (28). The weight of elastin in the aliquot was computed from the total of the contributions of its amino acids (31). The amount of collagen present was calculated from the hydroxyproline content of the soluble fraction. This was measured either from the peak of the amino acid analysis or by colorimetric determination (4). The amounts of elastin and collagen were calculated from the value computed from known aliquots and expressed in micrograms $(\mu \mathrm{g})$ per milligram $(\mathrm{mg})$ dry weight of lung.

\section{DATA ANAL.YSIS}

Statistical significance for all measurements was assessed by the paired $t$ test: probability values of $<0.05$ were considered significant.

\section{RESULTS}

Mean body weights and lengths are given in Table 1 . The mean body weight of the betamethasone-treated fetuses was not significantly different from that of the control (saline-treated) animals. The control group had three males $(43 \%)$, whereas the treated group had five $(71 \%)$. No significant differences in either the body lengths or head circumferences between the groups was noted. The mean adrenal to body weight ratio was significantly less in group II (betamethasone-treated) fetuses than in group I fetuses: however, the mean lung to body weight ratio was significantly greater in the group II animals compared to that of group I. No significant differences were noted between the betamethasoneand saline-treated fetuses for the following organ weights, expressed per gram of body weight: pancreas, thymus, spleen, and kidney. However, both the pancreas to body weight and thymus

Table 1. Morphometric Data

\begin{tabular}{|c|c|c|}
\hline & $\begin{array}{l}\text { Group I: } \\
\text { saline }\end{array}$ & $\begin{array}{c}\text { Group Il: } \\
\text { betamethasone }\end{array}$ \\
\hline Fetal body wt. (g) & $283.3 \pm 76.6^{1}$ & $262.8 \pm 56.7$ \\
\hline Sex ratio $(\mathrm{M} / \mathrm{F})$ & $3 / 4$ & $5 / 2$ \\
\hline Crown-heel length $(\mathrm{cm})$ & $23.8 \pm 2.7$ & $23.0 \pm 2.4$ \\
\hline Crown-rump length $(\mathrm{cm})$ & $16.2 \pm 1.4$ & $15.6 \pm 1.2$ \\
\hline Head circumference $(\mathrm{cm})$ & $16.7 \pm 1.3$ & $16.5 \pm 1.1$ \\
\hline $\begin{array}{l}\text { Adrenal wt/body } \\
\text { wt }(\mathrm{mg} / \mathrm{g})\end{array}$ & $0.749 \pm 0.127^{2}$ & $0.571 \pm 0.155$ \\
\hline $\begin{array}{l}\text { Lung wt/body } \\
\text { wt }(\mathrm{mg} / \mathrm{g})\end{array}$ & $19.6 \pm 2.11^{3}$ & $22.2 \pm 1.8$ \\
\hline $\begin{array}{l}\text { Kidney wt/body } \\
\text { wt (mg/g) }\end{array}$ & $5.77 \pm 0.64$ & $5.91 \pm 0.83$ \\
\hline $\begin{array}{l}\text { Spleen wt/body } \\
\text { wt }(\mathrm{mg} / \mathrm{g})\end{array}$ & $1.67 \pm 0.20$ & $1.70 \pm 0.29$ \\
\hline $\begin{array}{l}\text { Pancreas wt/body } \\
\text { wt }(\mathrm{mg} / \mathrm{g})\end{array}$ & $0.603 \pm 0.204$ & $0.434 \pm 0.069$ \\
\hline $\begin{array}{l}\text { Thymus wt/body } \\
\text { wt (mg/g) }\end{array}$ & $3.18 \pm 0.57$ & $2.44 \pm 0.73$ \\
\hline $\begin{array}{l}\text { Trimmed placenta } \\
\text { wt }(\mathrm{g})\end{array}$ & $84.2 \pm 20.8$ & $72.4 \pm 9.7$ \\
\hline
\end{tabular}

\footnotetext{
${ }^{1}$ Mean \pm S.D.

$2 P<0.05$.

${ }^{3} P<0.025$.
} 
to body weight ratios tended to be reduced in the glucocorticoidtreated animals as was found previously $(14,15)$.

\section{PRESSURE-VOLUME STUDIES}

Figure 1 illustrates the mean changes in volume on inflation and deflation for betamethasone-treated and control fetuses, ex-

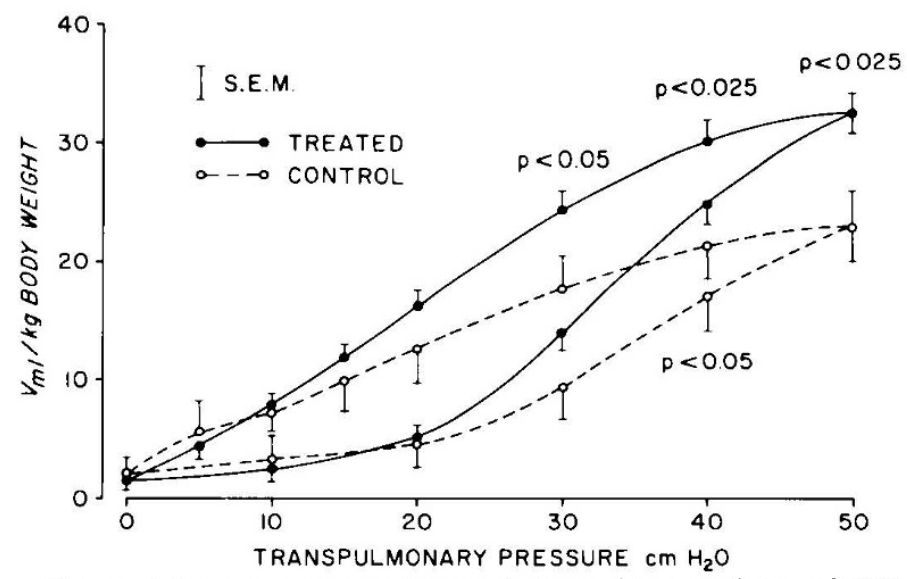

Fig. 1. Pulmonary-pressure volume studies. The mean lung volumes (in $\mathrm{ml}$ air) per $\mathrm{kg}$ of body weight tend to be higher in the animals treated with betamethasone. The lung volumes at a TPP inflation of $40 \mathrm{~cm}$ of water and at a TPP deflation of 40 and $30 \mathrm{~cm}$ water are significantly greater in the treated fetuses.

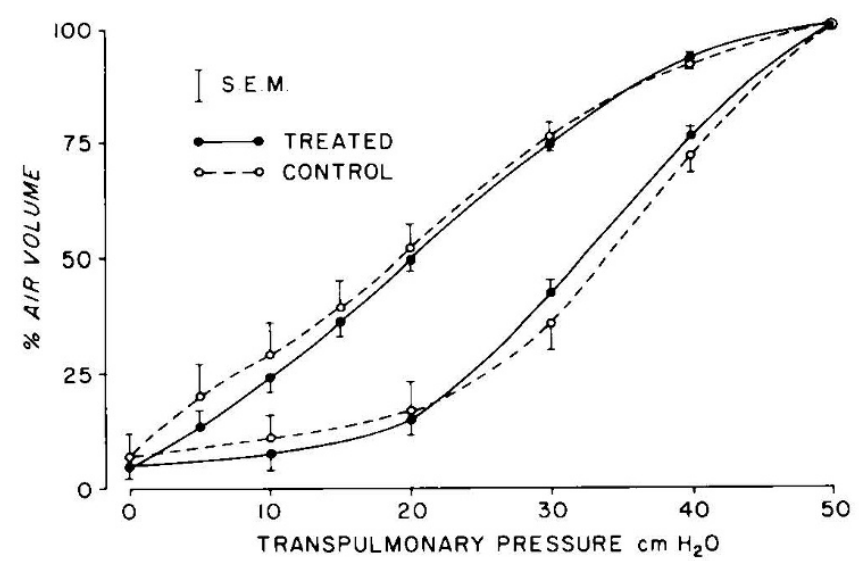

Fig. 2. Pulmonary pressure-volume studies. The mean proportionate lung volumes expressed as a percentage of the total lung volume for the betamethasone group are not statistically different from those of the saline injected group. pressed per kilogram of body weight. The mean maximal lung volume per kilogram of body weight at a TPP of $50 \mathrm{~cm}$ of water was signifcantly larger (about $40 \%$ ) in the treated fetuses compared to the controls. In addition, the absolute lung volumes at a TPP inflation of $40 \mathrm{~cm}$ of water and a TPP deflation of 40 and $30 \mathrm{~cm}$ of water were significantly greater in the glucocorticoid-treated animals compared to the controls.

However, when differences in lung volumes were corrected by expressing partial volumes as percentages of $\mathrm{V}_{\max } 50$ TPP during inflation and deflation (Fig. 2), the resulting curves were nearly superimposable. There were no significant differences between the treated and control fetuses in alveolar stability, as measured by air trapping on deflation. No significant correlations were obtained between $\mathrm{V}_{\max }$ /body weight for groups I and II and adrenal weight/body weight, lung weight/body weight, or amniotic fluid L/S.

The individual paired values for the maximal lung volume and the residual lung volume at $15 \mathrm{~cm} \mathrm{H}_{2} \mathrm{O}$ are given in Table 2. The maximal lung volume per kilogram of body weight in the control groups increased with gestational age, whereas that in the betamethasone-treated groups remained relatively constant.

\section{PULMONARY MORPHOMETRIC STUDIES}

Figure 3 is a composite of two low magnification photographs taken from the fixed sections from lungs of fetuses at 135 days' gestation. The overall visual perspective demonstrates the tendency for larger air spaces to be present in the lungs of the betamethasone-treated animal.

In an attempt to quantitate this difference, the mean number of alveoli per unit volume of lung and the mean internal surface area per unit volume of lung were determined using the mean linear intercept method. These two morphometric measurements are directly related because an increase in the number of alveoli per unit volume implies an increased surface area per unit volume. Figure 4 shows the alveolar surface area density as a function of gestational age for control and treated animals. The decrease in surface to volume ratio in the steroid-treated group is apparent. When all gestational ages are grouped we find a mean \pm S.E. decrease from $561 \pm 9 \mathrm{~cm}^{2} / \mathrm{cm}^{3}$ in the control group to $506 \pm 10$ $\mathrm{cm}^{2} / \mathrm{cm}^{3}$ in the treated group $(P<0.005)$. This morphometric result is supported by the results of alveolar number. The number of alveoli was decreased from a mean \pm S.E. of $1.19 \pm 0.08 \times$ $10^{6} / \mathrm{cm}^{3}$ in the control group to $0.95 \pm 0.07 \times 10^{6} / \mathrm{cm}^{3}$ in the treated animals $(P<0.025)$.

\section{BIOCHEMICAL STUDIES}

There were no significant differences between treated versus control animals, with respect to mean values of DNA, total phospholipid, phosphatidylcholine, sphingomyelin, collagen, or

Table 2. Functional and morphologic data illustrating the differences in control (group I) and betamethasone-treated (group II) animals ${ }^{1}$

\begin{tabular}{|c|c|c|c|c|}
\hline \multirow{2}{*}{$\begin{array}{l}\text { Gestational } \\
\text { Age (days) }\end{array}$} & \multicolumn{2}{|c|}{$\mathrm{V}_{\max } /$ body weight } & \multicolumn{2}{|c|}{$V_{15 \div 11^{2}}$} \\
\hline & I & II & I & II \\
\hline 110 & $13.03^{.}$ & 31.97 & $31.12^{1}$ & 32.10 \\
\hline 115 & 15.05 & 27.60 & 34.20 & 35.06 \\
\hline 120 & 18.24 & $28.57^{3}$ & 27.09 & $41.49^{3}$ \\
\hline 125 & $25.26^{3}$ & 39.74 & $31.03^{i}$ & 26.76 \\
\hline 130 & $34.42^{3}$ & 28.80 & $46.34^{:}$ & 26.48 \\
\hline 135 & $21.06^{3}$ & 37.82 & $26.30^{3}$ & 44.78 \\
\hline 140 & 33.49 & $33.46^{3}$ & 77.46 & $45.86^{3}$ \\
\hline Mean \pm S.E. & $22.94 \pm 3.21^{4}$ & $32.57 \pm 1.79^{5}$ & $39.10 \pm 6.87$ & $36.08 \pm 3.07$ \\
\hline
\end{tabular}

'The data are presented as a function of gestational age and treatment regimen. The maximal lung volume $\left(\mathrm{V}_{\operatorname{mux}}\right)$ is expressed in terms of $\mathrm{ml} / \mathrm{kg}$ of body weight.

${ }^{2} \mathrm{~V}_{\left.15^{\prime}, 1\right)}$ is the percentage of lung volume remaining after initial inflation to $50 \mathrm{~cm}$ of water, followed by deflation to $15 \mathrm{~cm}$ of water.

${ }^{3}$ Female animals.

${ }^{4}$ Mean \pm S.D.

${ }^{5} P<0.025$. 


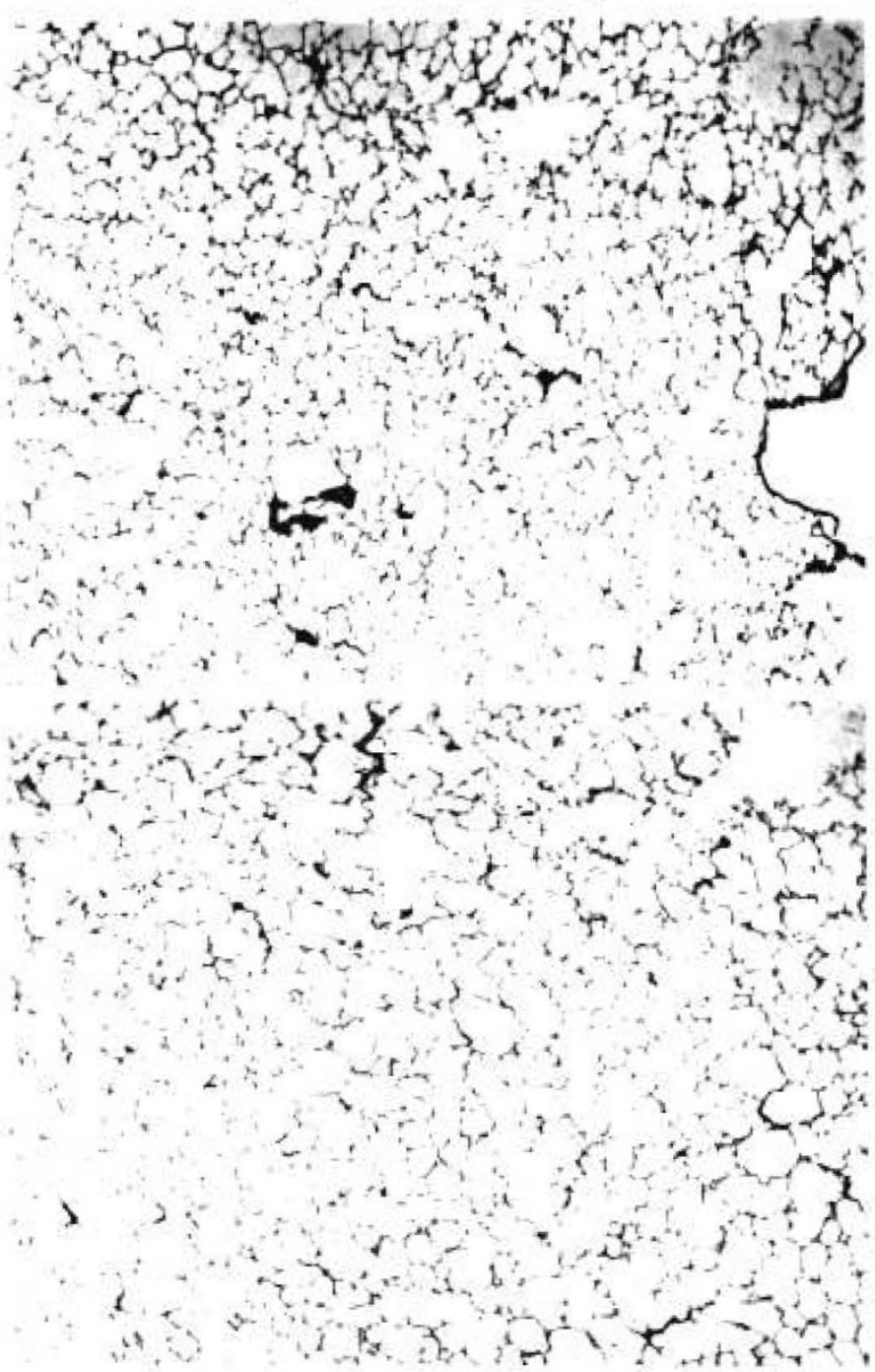

rig. 3. Light microscopy of lungs trom salıne injected group I (top) and betamethasone-treated group 11 (bottom) animals at 135 days' gestation. The areas are chosen to illustrate the larger alveolar size in the treated animal. The lungs have been fixed by warmed air distention through the bronchial tree, so that the alveolar walls appear thin. Sections are $6 \mu \mathrm{m}$ thick. (Hematoxylin and eosin; solid bar at top is equal to $1 \mathrm{~mm}$ ).

elastin expressed per milligram of wet lung tissue. Nor were there any differences in mean values of phospholipid, phosphatidylcholine, sphingomyelin, collagen, or elastin expressed per $\mu \mathrm{g}$ of lung DNA. There was, however, a significant increase in the amount of phosphatidylcholine relative to total lung phospholipid present in the betamethasone-treated lung (mean \pm S.E. of $0.337 \pm 0.017$ ) compared to that of the control animals (mean \pm S.E. of $0.290 \pm$ 0.010 ; Table 3).

With respect to connective tissue elements, the lungs of betamethasone-treated fetuses had increased collagen and decreased elastin concentrations, but there were no significant differences between control and treated groups. The collagen content in the lungs for both groups ranged from 60 to $90 \mu \mathrm{g} / \mathrm{mg}$ dry weight of lung; the elastin content in these same samples ranged from 25 to $40 \mu \mathrm{g} / \mathrm{mg}$ dry weight of lung. However, when the data were expressed as a ratio of collagen concentration to elastin concentration $(\mathrm{C} / \mathrm{E})$, the ratios were significantly increased in the lungs of the treated group $(2.24 \pm 0.08$ for group I versus $2.48 \pm 0.08$ for group II; Table 3). None of the biochemical parameters measured. i.e., lung phosphatidylcholine/phospholipid, (PC/PL), lung phosphatidylcholine/sphingomyelin, or $\mathrm{C} / \mathrm{E}$, correlated significantly with $\mathrm{V}_{\max } / \mathrm{kg}$ body weight.

\section{AMNIOTIC FLUID L/S RATIO}

The mean L/S ratio for group I was not significantly different from that of group II (Table 3 ). There was, however, a significant correlation between the amniotic fluid $\mathrm{L} / \mathrm{S}$ ratio and gestational age for both groups $(r=0.617 ; P<0.05)$.

\section{DISCUSSION}

The present study charts the effects of maternal betamethasone administration on rhesus fetuses over a broader gestational age (67 to $85 \%$ of pregnancy) than our previous studies $(14,15,21)$. The reduced adrenal weights observed in this study are in agreement with our previous findings $(14,15)$ and are consistent with the suppression of the hypothalamic-pituitary-adrenal axis produced by elevated fetal glucocorticoid plasma levels. Both the thymus weights and pancreas weights are less in the betamethasone-treated animals. Although these reductions in weight in the present study were not statistically significant, the trend is consistent with previous findings $(14,15)$.

The increased lung weight/body weight ratio in the treated animals $(22.2 \pm 1.8 \mathrm{~g} / \mathrm{kg})$ versus the saline controls $(19.6 \pm 2.1 \mathrm{~g} /$ $\mathrm{kg} ; P<0.025)$ is a result we have not found in previous studies of betamethasone-treated fetuses. We cannot offer a satisfactory explanation of this finding in the present study because there were no statistically significant changes in lung or body weights. The increase in lung weight to body weight was $13 \%$ and the physiologic significance of this increase is unclear.

In agreement with our previous studies $(14,15,21)$, we observed a significant increase in the maximal lung volumes in the rhesus fetuses after betamethasone treatment. However, in this study, we found no changes in either the residual lung volumes on deflation $\left(\mathrm{V}_{15, \mathrm{n}}\right)$ or amniotic fluid $\mathrm{L} / \mathrm{S}$ and only minimal changes in $\mathrm{PC} /$ PL after betamethasone treatment. These results are in apparent conflict with studies reported in other species and in in vitro lung cultures. There are several possibilities for this discrepancy.

Recent animal $(17,22)$ and clinical $(3,23)$ studies have suggested that there may be different rates of lung maturation for males and females and that males and females may respond differently to the glucocorticoid induction of this process. Although the male to female ratio was not significantly different between the two groups of this study (Table 1), the treated group had more males. We have examined the data on 20 Macaca mulatta fetuses from a previous study at the same gestational age ( $82 \%$ of pregnancy) to determine the effect of sex differences and betamethasone treatment. We have found that in this species there is no statistically

EFFECT OF BETAMETHASONE ON SURFACE AREA DENSITY

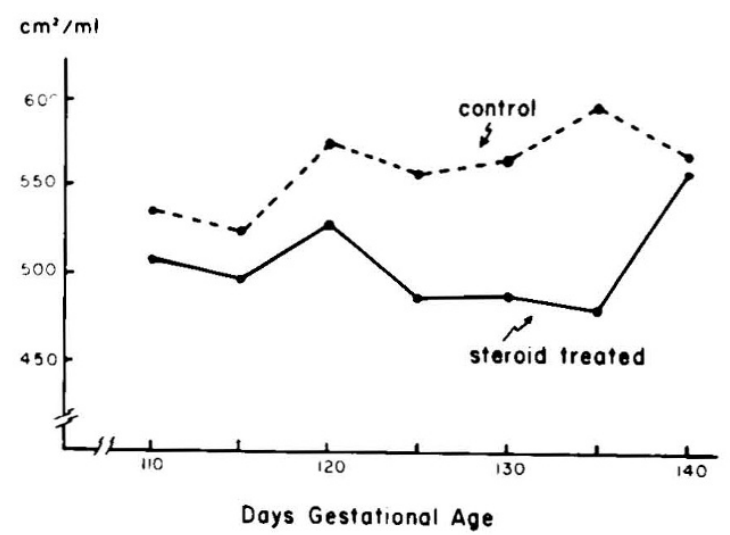

Fig. 4. Morphometric data. The mean internal surface area per unit volume of lung plotted as a function of gestational age illustrates that at each gestational age the glucocorticoid-treated fetuses have less internal surface area per unit volume of lung. 
Table 3. Biochemical data illustrating the differences in control (group I) and the betamethasone-treated (group II) animals ${ }^{1}$

\begin{tabular}{|c|c|c|c|c|c|c|}
\hline & \multicolumn{2}{|c|}{$\mathrm{PC} / \mathrm{PL}$} & \multicolumn{2}{|c|}{$\mathrm{C} / \mathrm{E}$} & \multicolumn{2}{|c|}{ Amniotic fluid $L / S$} \\
\hline & 1 & II & I & II & I & II \\
\hline 110 & $0.307^{2}$ & 0.309 & $2.50^{2}$ & 2.75 & $0.4^{2}$ & 0.5 \\
\hline 115 & 0.266 & 0.290 & 1.99 & 2.50 & 0.3 & 0.4 \\
\hline 120 & 0.254 & $0.339^{2}$ & 2.36 & $2.28^{2}$ & 0.5 & $0.4^{2}$ \\
\hline 125 & $0.279^{2}$ & 0.295 & $1.90^{2}$ & 2.12 & $0.5^{2}$ & 0.4 \\
\hline 130 & $0.318^{2}$ & 0.335 & $2.24^{2}$ & 2.39 & $0.3^{2}$ & 0.5 \\
\hline 135 & $0.329^{2}$ & 0.367 & $2.30^{2}$ & 2.77 & $0.8^{2}$ & \\
\hline 140 & 0.275 & $0.427^{2}$ & 2.37 & & 0.9 & 1.0 \\
\hline & & & & $2.53^{2}$ & & $0.5^{2}$ \\
\hline Group & $0.290 \pm 0.01$ & $0.337 \pm 0.017^{3}$ & $2.24 \pm 0.08$ & & $0.53 \pm 0.22$ & \\
\hline Mean \pm S.E. & & & & $2.48 \pm 0.08^{4}$ & & $0.53 \pm 0.20$ \\
\hline
\end{tabular}

${ }^{\prime} \mathrm{C} / \mathrm{E}, \mathrm{PC} / \mathrm{PL}$, and $\mathrm{L} / \mathrm{S}$ ratios are given as a function of gestational age and treatment regimen.

${ }^{2}$ Female animals.

${ }^{3} P<0.05$.

${ }^{4} P<0.01$.

significant difference in $\mathrm{V}_{\max } / \mathrm{kg}$ of body weight or residual lung volume between males and females. Furthermore, male and female fetuses exhibit approximately the same percentage change after betamethasone treatment. Therefore, the fact that we have not found significant differences in deflation stability or amniotic fluid $\mathrm{L} / \mathrm{S}$ ratios cannot be explained by differences in the sex ratio between the control and treated groups.

Another possible explanation for the discordance with other investigators may be our failure to quantitate the disaturated phosphatidylcholine content, presumably a better marker for surfactant synthesis than total lung phosphatidylcholine. However, in our previous studies we have found significant correlations between total phosphatidylcholine content and functional indices of surfactant, i.e., minimum extract surface tension values and lung deflation characteristics (15).

The fact that the present study contrasts with a number of studies could be related to species differences, to differences in the intact animal, and to method of glucocorticoid administration. A number of studies have indicated that hyperinsulinemia may interfere with lung maturation and surfactant acceleration (11). We have recently ascertained that striking hyperinsulinemia occurs in our steroid-treated animal preparation (13). This clearly would not be observed in in vitro preparations and may not occur where the glucocorticoid is administered directly to the fetus, rather than to the mother. Further studies are in progress to determine whether the hyperinsulinemia observed in this rhesus model might account for an apparent minimal effect of glucocorticoids on pulmonary surfactant.

In a previous study (15), we found a $40 \%$ increase in residual lung volume $\left(\mathrm{V}_{15 \% \mathrm{D}}\right)$ and a $20 \%$ increase in the $\mathrm{PC} / \mathrm{PL}$ ratio after betamethasone treatment. In the present study, we observed no significant change in $\mathrm{V}_{15,5 \mathrm{D}}$ after treatment and a smaller increase in $\mathrm{PC} / \mathrm{PL}(16 \%)$, after maternal betamethasone administration. This recent study encompasses a broader (and earlier) gestational range ( 67 to $85 \%$ of pregnancy) than the previous one ( 75 to $85 \%$ ). It is possible that there is a gestational age difference in betamethasone sensitivity and that this may explain the apparent inconsistencies in these two studies. Our inability to demonstrate changes in alveolar stability (residual volumes on deflation) and amniotic fluid $\mathrm{L} / \mathrm{S}$ ratios suggest that lung surfactant changes are of lower magnitude and functional consequence than lung structural changes. It has been our hypothesis that the large increases in lung volumes are due primarily to alterations in the structural architecture $(14,15,21)$, rather than the surface lining, based on our observations that changes in residual lung volumes on deflation and lung phospholipid concentrations are much less striking. It is not clear to us how changes in alveolar surface tension could bring about such striking increases in maximal lung volumes. Bachofen et al. (1) noted little, if any, change in maximal lung volume of excised rabbit lungs after marked increases in alveolar surface tension were effected by rinsing with a detergent. The fact that increased lung volumes are observed even with saline filling when surfactant effects are nullified (21) provides the most positive evidence that betamethasone affects tissue elements directly.

Although the results of the present study show evidence of increased distensibility of individual alveoli, we still cannot exclude the possibility that some of the increased lung volume occurs because of an increased number of alveoli. The reason for this relates to the fact that we made no measurement of the lung volume after the lungs were fixed. Also, because the sections for morphometric analysis are cut from the fixed lung, we cannot directly relate these data to the pressure-volume curves done in the intact lungs. If we make the assumption that there were no systematic fixation differences between the control and the steroidtreated groups, then we may speculate on the degree of alveolar recruitment and distensibility. A $20 \%$ decrease in alveolar number per unit volume implies that an individual alveolus is increased in volume by about $25 \%$. This increase in size is insufficient to account for the greater than $40 \%$ increase in maximal lung volume found in this study and up to $100 \%$ increases found in previous work (15). Therefore, to account for the entire increase in lung air volume, it is likely that there was also an increase in the number of alveoli recruited. However, at the present time, it is impossible to be precise regarding the mechanism of the increased lung volumes seen after betamethasone treatment. What is needed is a study where lung volumes are controlled during the fixation procedure. so that the morphometric results can be more directly related.

Dexamethasone has been reported to inhibit collagenase production, thereby decreasing collagen degradation and resulting in a net increase in collagen content (8). The betamethasone-treated fetuses in this study had increased collagen and decreased elastin concentrations compared to controls. Although these findings were not significantly different, they are similar to findings reported previously in studies on emphysematous lungs $(5,18,25)$. The fact that steroid treatment increased the $\mathrm{C} / \mathrm{E}$ ratio by $11 \%$ is consistent with some type of structural change and tends to support the morphometric data. Reduced numbers of alveoli and alveolar surface area per unit lung volume, as well as increased maximal lung volumes, have been reported in experimentally produced emphysema $(18,26,27)$. Although alterations in the $C$ / E ratio might be expected to cause functional alterations in the pressure-volume curve, it is very difficult to define a specific correlation. The functional effect of changes in the elastin and collagen content of lung tissue is complex. The simple model, with elastin fibers in parallel with collagen fibers arranged such that the collagen fibers are stressed only at high lung volumes (20) may be inadequate to describe the actual lung architecture. Indeed, the recent work of Snider et al. (27) shows a significant increase in maximal lung volume after elastase treatment, an increase which 
was considerably larger than the increase seen after collagenase treatment. In light of this work, our findings of increased maximal lung volume are consistent with an increased $\mathrm{C} / \mathrm{E}$ ratio. However, with the increased $\mathrm{C} / \mathrm{E}$ ratio, we also should have seen an increase in the deflation stability due to this structural alteration. We found no such change in the present study, although we did note them in a prior study. Failure to observe them in the current study might be explained by differences in gestational age.

In summary, we have collected functional data (pressure-volume characteristics), biochemical data (C/E concentration), and morphometric data, which are consistent with the hypothesis that there are significant connective tissue changes occurring in the fetal lung in response to glucocorticoid (betamethasone) therapy. The increase in $\mathrm{C} / \mathrm{E}$ ratio and the increase in maximal lung volumes generally simulate human emphysema. Although these changes may be transitory ones which occur only during elevated plasma betamethasone concentrations, the process of repair after betamethasone treatment must be considered. After elastase-induced emphysema. lungs depleted of elastin will acquire a normal elastin content within 2 months, but the organization of the elastic fiber network is not restored to normal, and permanent anatomical deformity of the lung results (18). This comparison of elastaseinduced emphysema and the effect of glucocorticoid on the developing lung should be interpreted cautiously, as there may be both quantitative and qualitative differences. However, the possibility that the comparison does have some validity should be kept in mind. Additional work will be needed to evaluate the long-term effect of the changes we have found in the present investigation.

\section{REFERENCES AND NOTES}

I. Bachofen. H., Gehr. P.. and Weibel. E. R.: Alterations of mechanical properties and morphology in excised rabbit lungs rinsed with a detergent. J. Appl. Physiol. Respir. Environ. Exercise Physiol. 47: 1002 (1979).

2. Ballard R. A., and Ballard. P. L.: The use of betamethasone in the prevention of RDS. In: A. I. Goldstein: Advances in Perinatal Medicine. pp. 77-87 (Stratton Intercontinental Book (orp.. New York, 1977).

3. Ballard P. L.. Ballard, R. A.. Granberg. J. P.. and Sniderman, S.: Sex and prenatal betamethasone therapy for respiratory distress syndrome (RDS) Pediatr. Res.. 14: 589a (1980).

4. Bergman. I., and Loxley, R.: Lung tissue hydrolysates: studies of the optimum conditions for the spectrophotometric determination of hydroxyproline. Analyst. 94: 575 (1969).

5. Briscoe, A. M., and Loring. W. E.: Elastin content of the human lung. Proc. Soc. Exp. Biol. Med., 99: 162 (1958).

6. Cheek. D. B.: Brain lipid extraction. In: Fetal and Postnatal Cellular Growth. pp 509-510) (John Wiley and Sons. Inc., New York. 1975).

7. (heek. D. B.: Desoxyribonucleic acid (DNA). In: Fetal and Postnatal Cellular Growth. pp. 503-505 (John Wiley \& Sons. Inc., New York. 1975).

8. Dayer, J.-M.. Krone. S. M.. Russell, R. G. G.., and Robinson, D. R.: Production of collagenase and prostaglandins by isolated adherent rheumatoid synovial cells. Proc. Natl. Acad. Sci. U. S. A.. 7.3: 945 (1976).

9. Fisher, G. M., and Llaurado. J. G.: Collagen and elastin content in canine arteries selected from functionally different vascular beds. (irc. Res., 19: 394 (1966).

10. Folch, J.. Lees. M.. and Sloane-Stanley. C. H.: A simple method for the isolation and purification of total lipides from animal tissues. J. Biol. Chem., 226: 497 (1957).

11. Frantz. I. D., and Epstein. M. F.: Fetal lung development in pregnancies complicated by diabetes. Semin. Perinatol.. 2: 347 (1978).
12. Goldner. R. D.. and Brumley. G. W.: Comparative incorporation of ${ }^{.2} \mathrm{P}$ into lung phosphatidylcholine in mammals with different metabolic and pulmonary morphologic characteristics. Proc. Soc. Exp. Biol. Med.. 145: 1343 (1974).

13. Johnson. J. W. C. Mitzner, W. Beck, J. C. Lee, P. A. London, W. T., and Sly, D. L.: Betamethasone and the rhesus fetus: alterations in maternal-fetal carbohydrate homeostasis. (In preparation).

14. Johnson. J. W. C.. Mitzner, W.. London, W. T., Palmer. A. E., and Scott. R. Betamethasone and the rhesus fetus: multisystemic effects. Am. J. Obstet. Gynecol., 133: 677 (1979).

15. Johnson, J. W. C.. Mitzner, W., London. W. T., Palmer. A. E., Scott, R., and Kearney, K.: Glucocorticoids and the rhesus fetal lung. Am. J. Obstet. Gynecol., 1.30): 905 (1978).

16. Kissane, J. M., and Robbins, E.: The fluorometric measurement of deoxyribonucleic acid in animal tissues with special reference to the central nervous system. J. Biol. (hem., 233: 184 (1958).

17. Kotas. R. V.. and Avery. M. E.: The influence of sex on fetal rabbit lung maturation and on the response to glucocorticoid. Am. Rev. Respir. Dis.. 121: 377 (1980).

18. Kuhn. C.. Yu, S.-Y.. Chraplyvy, M.. Linder, H. E., and Senior, R. M.: The induction of emphysema with elastase. II. Changes in connective tissue. Lab. Invest.. 34: 372 (1976)

19. Lansing, A. I., Rosenthal, T. B., Alex, M. and Dempsey, E. W.: The structure and chemical characterization of elastic fibers as revealed by elastase and electron microscopy. Anat. Rec., 114: 555 (1953).

20. Mead. J.: Mechanical properties of lungs. Physiol. Rev.. 41: 281 (1961).

21. Mitzner, W., Johnson. J. W. C.. Scott. R. London, W. T., and Palmer, A. E Effect of betamethasone on pressure-volume relationships of fetal rhesus monkey lung. J. Appl. Physiol.: Respir. Environ. Exercise Physiol., 47: 377 (1979).

22. Nielsen, H. C.., and Torday, J. S.: Ontogeny of surfactant production: a lag in the male rabbit fetus. Pediatr. Res., 14: 459a (1980).

23. Papageorgiou. A. N.. Colle. E., Gelfand. M. M.: Incidence of RDS following betamethasone $(B)$ : the role of sex, type of delivery and prolonged rupture of the membranes (PROM). Pediatr. Res., 14: 649a (1980).

24. Parker. F.. and Peterson. N. F.: Quantitative analysis of phospholipids and phospholipid fatty acids from silica gel thin-layer chromatograms. J. Lipid. Res., 6: 455 (1965).

25. Pecora, L. J., Manne, W. R., Baum, G. L., Feldman, D. P., and Recavarren, S Biochemical study of ground substances in normal and emphysematous lungs. Am. Rev. Respir. Dis., 95: 623 (1967).

26. Snider. G. L.., and Korthy. A. L.: Internal surface area and number of respiratory air spaces in elastase-induced emphysema in hamsters. Am. Rev. Respir. Dis. 117: 685 (1978).

27. Snider, G. L. Sherter C. B. Koo, K. W. Karlinsky, J. B. Hayes, J. A.. and Franzblau. C.: Respiratory mechanics in hamsters following treatment with endotracheal elastase or collagenase. J. Appl. Physiol., 42: 206 (1977).

28. Spina, M. Garbin. G.. Field. J. M., and Serafini-Fracassini, A.: The application of collagenase purified by affinity chromatography to the isolation of insoluble elastin from bovine aorta. Biochim. Biophys. Acta, 400: 162 (1975).

29. Weibel, E. R.: Morphometry of the Human Lung. p. 35 (Academic Press, Inc. New York, 1963).

30. Weibel, E. R., and Gomez, C. R.: A principle for counting tissue structures on random sections. J. Appl. Physiol., 17: 343 (1962).

31. Wolinsky. H.: Effects of hypertension and its reversal on the thoracic aorta of male and female rats. Circ. Res., 28: 622 (1971).

32. Dr. Mitzner is a recipient of National Institutes of Health Research Career Development Award HL-(10347.

33. Dr. Foidart was a visiting Associate at the Laboratory of Developmental Biology and Abnormalities of the National Institute of Dental Research and presently is a Fellow of the Fondo National de la Recherche Scientifique in Belgium.

34. The authors express their appreciation to Patricia Murphy for her excellent assistance in the preparation of this manuscript.

35. Requests for reprints should be addressed to: Jeanne C. Beck. Ph.D.. 108 Harvey Building. Johns Hopkins Hospital, Baltimore. MD 21205 (USA).

36. This research was supported in part by National Institutes of Health Grant HD 04050.

37. Received for publication April 10, 1980.

38. Accepted for publication September 16, 1980 